\title{
Autophosphorylation of serine 608 in the p85 regulatory subunit of wild type or cancer- associated mutants of phosphoinositide 3-kinase does not affect its lipid kinase activity
}

\author{
Meredith J Layton', Mirette Saad², Nicole L Church, Richard B Pearson ${ }^{1,3,4,6}$, Christina A Mitchell ${ }^{1}$ \\ and Wayne A Phillips ${ }^{1,2,4,5^{*}}$
}

\begin{abstract}
Background: The a-isoform of the Type 1A Phosphoinositide 3-kinases (PI3Ka) has protein kinase activity as well as phosphoinositide lipid kinase activity. The best described substrate for its protein kinase activity is its regulatory subunit, p85a, which becomes phosphorylated on Serine 608. Phosphorylation of Serine 608 has been reported to down-regulate its lipid kinase activity.

Results: We have assessed whether oncogenic mutants of PI3Ka, which have up-regulated lipid kinase activity, have altered levels of Serine 608 phosphorylation compared to wild type PI3Ka, and whether differential phosphorylation of Serine 608 contributes to increased activity of oncogenic forms of PI3Ka with point mutations in the helical or the kinase domains. Despite markedly increased lipid kinase activity, protein kinase activity was not altered in oncogenic compared to wild type forms of PI3Ka. By manipulating levels of phosphorylation of Serine 608 in vitro, we found no evidence that the protein kinase activity of PI3Ka affects its phosphoinositide lipid kinase activity in either wild-type or oncogenic mutants of PI3Ka.
\end{abstract}

Conclusions: Phosphorylation of p85a S608 is not a significant regulator of wild-type or oncogenic PI3Ka lipid kinase activity.

Keywords: PI3K, PIK3CA, Phosphoinositide, Kinase, Mutation, Oncogene, Phosphorylation

\section{Background}

Phosphoinositide 3-kinases (PI3Ks) are a ubiquitous family of lipid kinases that catalyse the phosphorylation of phosphoinositide lipids at the 3' position on the inositide ring [1]. The Class 1A sub-group exists as heterodimers of a p110 catalytic subunit and a p85 regulatory subunit that can phosphorylate three phosphoinositides (PI, PI-(4)-P and PI- $\left.(4,5)-\mathrm{P}_{2}\right)$ in vitro, but are thought to primarily phosphorylate $\mathrm{PI}-(4,5)-\mathrm{P}_{2}$ in vivo to form PI- $(3,4,5)-\mathrm{P}_{3}$ $\left(\mathrm{PIP}_{3}\right)$ [1]. $\mathrm{PIP}_{3}$ resides almost exclusively in the plasma membrane and propagates signals by recruiting and

\footnotetext{
*Correspondence: wayne.phillips@petermac.org

'The Department of Biochemistry and Molecular Biology, Monash University, Clayton, VIC 3800, Australia

${ }^{2}$ Surgical Oncology Research Laboratory, Peter MacCallum Cancer Centre, St Andrew's Place, East Melbourne, VIC 3002, Australia

Full list of author information is available at the end of the article
}

activating a variety of downstream proteins that contain $\mathrm{PIP}_{3}$ binding domains (primarily Pleckstrin Homology $(\mathrm{PH})$ domains) [2]. PI3K/PIP 3 signalling regulates a wide range of cellular processes including cell growth, survival, glucose metabolism and migration $[1,3]$.

The prototypic Class 1A PI3K is a heterodimer of the $\alpha$ isoforms of $\mathrm{p} 110$ and $\mathrm{p} 85$ (p110 $\alpha / \mathrm{p} 85 \alpha$ or PI3K $\alpha)$. Mutations in PIK3CA, the gene encoding $\mathrm{p} 110 \alpha$, are oncogenic [4-7] and are frequently reported in breast and colon cancers, where they are found in around $25 \%$ of human tumours [8-11]. Tumour-associated PIK3CA mutations are all somatic, mono-allelic single base changes that result in single amino acid substitutions. The majority $(>80 \%)$ of mutations cluster in exon 9 (which codes for the helical domain) or exon 20 (which codes for the kinase domain), most commonly E542K 
and E545K in exon 9 and H1047R in exon 20 [4,12]. Cancer-associated, mutated forms of PI3K $\alpha$ are associated with increased phosphoinositide kinase activity [4-6,13], leading to up-regulation of downstream signalling events such as phosphorylation of Akt and S6 [5,14].

Class 1A PI3Ks also have protein kinase activity. The p110 $\alpha$ catalytic subunit can phosphorylate its regulatory subunit, p85 $\alpha$, at Serine 608 (S608). Phosphorylation of this site has been reported to result in feed-back inhibition by down-modulating the lipid kinase activity of p110 $\alpha$ [15-17], however the role of phosphorylation of S608 in signalling by endogenous PI3K $\alpha$ and the structural mechanism of down-modulation of lipid kinase activity by $\mathrm{S} 608$ phosphorylation are not well described. We have assessed the possibility that the increased lipid kinase activities of oncogenic mutants of PI3K $\alpha$ could be partly due to alterations in the phosphorylation of S608. Rather than make point mutations in S608, which can potentially subtly alter the structure and thus the activity of $\mathrm{p} 110 \alpha / \mathrm{p} 85 \alpha$ heterodimers, we have manipulated the levels of phosphorylation of $\mathrm{S} 608$ of highly-purified, recombinant $\mathrm{p} 110 \alpha / \mathrm{p} 85 \alpha$ in vitro and tested the effect on lipid kinase activity. Neither complete dephosphorylation nor a high percentage occupancy of S608 by a phosphate group significantly altered the lipid kinase activity of wild-type PI3K $\alpha$. The levels and kinetics of S608 phosphorylation in two oncogenic mutants, E545K and H1047R, were not significantly different to that of wildtype $\mathrm{p} 110 \alpha / \mathrm{p} 85 \alpha$ and the lipid kinase activities of mutant PI3K $\alpha$ were similarly unaffected by phosphorylation of S608. This suggests that phosphorylation of S608 is not a significant regulator of PI3K $\alpha$ lipid kinase activity.

\section{Results}

Expression, purification and characterisation of recombinant wild-type and mutant $\mathrm{PI} 3 \mathrm{Ka}$

The same strategy that was used to express and purify active, recombinant bovine $\mathrm{p} 110 \alpha / \mathrm{p} 85 \alpha$ [18] was used to generate human, C-terminally EE-tagged, full length, wild-type $\mathrm{p} 110 \alpha / \mathrm{p} 85 \alpha$ in Sf9 insect cells using the Bac-N-Blue baculovirus system. When Sf9 cells were coinfected with baculoviruses encoding both subunits, p85 was expressed at higher levels than p110 $\alpha E E$, therefore to obtain purified $\mathrm{p} 110 \alpha \mathrm{EE} / \mathrm{p} 85 \alpha$, affinity chromatography using an antibody directed against the epitope tag (EE $\mathrm{mAb}$ ) was used to capture the enzyme complex but not excess p $85 \alpha$. Competitive elution with an EE-tag peptide (EYMPME), followed by anion exchange chromatography were performed as described [18]. PI3K purified in this way comprises a homogeneous 1:1 complex of the $\mathrm{p} 110 \alpha$ and $\mathrm{p} 85 \alpha$ subunits as assessed by both SDS-PAGE (Figure 1A) and analytical size exclusion chromatography [18]. Recombinant p110 $\alpha E E / p 85 \alpha$ was estimated to be $>95 \%$ pure based on densitometry of the relative levels of all Coomassie blue-stained bands in each lane and no peptides other than those derived from p $110 \alpha E E$ or $p 85 \alpha$ were detected by LC-MS/MS of tryptic digests of the purified recombinant complex. We have also expressed and purified to homogeneity EE-tagged complexes of $\mathrm{p} 85 \alpha$ with $\mathrm{p} 110 \alpha$ containing two of the most common cancer-associated mutations from two different regions of $\mathrm{p} 110 \alpha$ (E545K in exon 9 and H1047R in exon 20) (Figure 1A).

Oncogenic mutants of $\mathrm{PI} 3 \mathrm{~K} \alpha$ have been reported to have higher lipid kinase activity than wild-type [4-6,13].

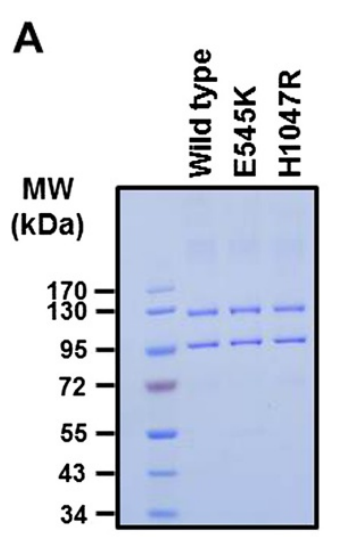

B

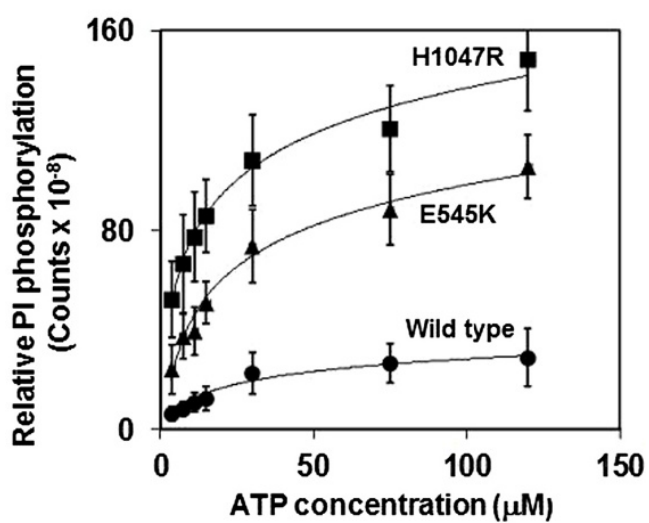

Figure 1 Characterisation of purified, recombinant PI3Ks. A. SDS-PAGE and Coomassie Blue staining of molecular weight standards

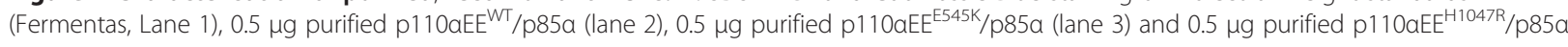
(lane4). B. Purified, recombinant PI3Ks were assayed for lipid kinase activity with increasing concentrations of ATP using PI-(4,5)- $P_{2}$ as a substrate. Reactions were stopped after 20 minutes using $1 \mathrm{M} \mathrm{HCl}$. The amount of ${ }^{32} \mathrm{P}-\mathrm{PI}-(3,4,5)-\mathrm{P}_{3}$ generated was quantified using a phosphorimager and displayed as mean \pm SEM, $\mathrm{n}=4$. 
As shown previously $[15,19]$, recombinant forms of the $\mathrm{p} 110 \alpha E E^{\mathrm{E} 545 \mathrm{~K}} / \mathrm{p} 85 \alpha$ and $\mathrm{p} 110 \alpha E E^{\mathrm{H} 1047 \mathrm{R}} / \mathrm{p} 85 \alpha$ complexes have higher lipid kinase activities than $\mathrm{p} 110 \alpha \mathrm{EE}^{\mathrm{WT}} /$ p85 $\alpha$. The H1047R mutant had higher activity than the E545K mutant (Figure 1B). Kinetic parameters were derived for recombinant wild type and mutant p110 $\alpha E$ / p $85 \alpha$ complexes by varying the concentration of ATP and measuring initial reaction rates (Table 1), and showed that, when PI was used as the substrate, the $K_{m}$ for H1047R and E545K were similar to wild type. When PI-(4,5)- $P_{2}$ was used as a substrate, the $K_{m}$ for H1047R was decreased approximately 2 -fold compared to wild type, but that for E545K was not significantly different. Both mutants showed a significant 3 to 4-fold increase in $\mathrm{V}_{\max }$ when either PI or PI- $(4,5)-\mathrm{P}_{2}$ was used as a substrate, with the $V_{\max }$ for $\mathrm{H} 1047 \mathrm{R}$ being significantly higher than that for E545K (Table 1). The kinetic characteristics of purified, recombinant, EE-tagged forms of wild-type and mutant PI $3 \mathrm{~K} \alpha$ are therefore essentially the same as those previously reported for purified, recombinant His-tagged forms of PI3K $\alpha[15,19]$ and endogenous wild-type and mutant PI3K $[4,5]$.

\section{Effect of dephosphorylation of p85a S608 on PI3Ka lipid kinase activity}

S608 in the p85 subunit is a substrate for the protein kinase activity of PI3K $\alpha[17,20]$. Phosphorylation of S608 by 110 is reported to down-regulate PI3K $\alpha$ lipid kinase activity $[17,20]$. This raises the possibility that higher lipid kinase activities of oncogenic mutants of PI3K $\alpha$ could be partly due to alterations in the levels of phosphorylation of S608.

To better compare lipid kinase activities of wild-type and mutant PI3Ka that were phosphorylated or unphosphorylated at S608, we opted to manipulate phosphorylation levels of recombinant $\mathrm{p} 110 \alpha E E / \mathrm{p} 85 \alpha$ complexes in vitro rather than to make point mutations in S608. To perform lipid kinase assays with dephosphorylated PI3K $\alpha$, it was necessary to find a phosphatase that dephosphorylated $\mathrm{p} 85 \alpha$ but not inositol lipids. We

\begin{tabular}{|c|c|c|c|c|}
\hline & & Wild type & E545K & H1047R \\
\hline \multirow[t]{2}{*}{ PI kinase activity ${ }^{a}$} & $V_{\max }^{b}$ & $35 \pm 13^{c}$ & $118 \pm 12$ & $150 \pm 13$ \\
\hline & $\mathrm{K}_{\mathrm{m}}(\mu \mathrm{M})$ & $23 \pm 3$ & $22 \pm 6$ & $14 \pm 7$ \\
\hline \multirow[t]{2}{*}{$\mathrm{PI}-(\mathbf{4}, 5)-\mathrm{P}_{2}$ kinase activity } & $\mathrm{V}_{\max }$ & $35 \pm 8$ & $117 \pm 13$ & $146 \pm 15$ \\
\hline & $\mathrm{K}_{\mathrm{m}}(\mu \mathrm{M})$ & $22 \pm 5$ & $19 \pm 6$ & $9 \pm 3$ \\
\hline
\end{tabular}

${ }^{\mathrm{a}} \mathrm{PI}$ or $\mathrm{PI}-(4,5)-\mathrm{P}_{2}$ were used as substrates to generate $\mathrm{PI}-3-\mathrm{P}$ or $\mathrm{PI}-(3,4,5)-\mathrm{P}_{3}$. ${ }^{\mathrm{b}}$ Michaelis-Menten kinetic parameters (substrate affinity $\left(\mathrm{K}_{\mathrm{m}}\right)$ and maximum reaction velocity $\left(\mathrm{V}_{\text {max }}\right)$ ) for the production of $\mathrm{PI}-3-\mathrm{P}$ or $\mathrm{PI}-(3,4,5)-\mathrm{P}_{3}$ were calculated from assays in which the concentration of ATP was varied. ${ }^{c} K_{m}$ and $V_{\text {max }}$ are shown as mean $\pm S E M, n=4$. compared three different protein phosphatases (Figure 2A). We have previously used Antarctic Phosphatase to dephosphorylate affinity-precipitated proteins for characterisation on 2D gels [21], however Antarctic Phosphatase was inactive at temperatures $>4^{\circ} \mathrm{C}$ that are required for significant lipid and protein kinase activity of PI3K $\alpha$, and so had no effect on levels of phosphorylation of $\mathrm{p} 85 \alpha$ or PI at room temperature (Figure 2A). Alkaline phosphatase is a broad spectrum phosphatase that was able to dephosphorylate both S608 and PI-3-P. In contrast, recombinant $\lambda$ phosphatase dephosphorylated S608 but not PI-3-P (Figure 2A). $\lambda$ phosphatase was therefore added to PI kinase assays to continually remove phosphate groups from S608 and allow comparison of the lipid kinase activity of phosphorylated and dephosphorylated PI3K $\alpha$.

As expected, inclusion of $\lambda$ phosphatase in kinase assays resulted in no significant incorporation of ${ }^{32} \mathrm{P}$-labelled phosphate groups into $\mathrm{p} 85 \alpha$, demonstrating that levels of $\mathrm{p} 85 \alpha$ phosphorylation were low in the presence of $\lambda$ phosphatase (Figure 2B, upper panel). Dephosphorylated $\mathrm{p} 110 \alpha \mathrm{EE}^{\mathrm{WT}} / \mathrm{p} 85 \alpha$ did not have a significantly different PI kinase activity to $\mathrm{p} 110 \alpha \mathrm{EE}^{\mathrm{WT}} / \mathrm{p} 85 \alpha$ that became phosphorylated on p85 $\alpha$ over the course of the assay (Figure 2B, lower panel). Similarly, the E545K and H1047R mutants did not have significantly different PI kinase activities when p85 $\alpha$ was either dephosphorylated or phosphorylated, although the PI kinase activities of $\mathrm{p} 110 \alpha \mathrm{EE}^{\mathrm{E} 545 \mathrm{~K}} / \mathrm{p} 85 \alpha$ and $\mathrm{p} 110 \alpha \mathrm{EE}^{\mathrm{H} 1047 \mathrm{R}} / \mathrm{p} 85 \alpha$ were higher than that of $\mathrm{p} 110 \alpha \mathrm{EE}^{\mathrm{WT}} / \mathrm{p} 85 \alpha$ as expected (Figure $2 \mathrm{~B}$, lower panel). Interestingly, as observed previously [15], the protein kinase activities of $\mathrm{p} 110 \alpha \mathrm{EE}^{\mathrm{E} 545 \mathrm{~K}} / \mathrm{p} 85 \alpha$ and $\mathrm{p} 110 \alpha \mathrm{EE}^{\mathrm{H} 1047 \mathrm{R}} / \mathrm{p} 85 \alpha$ were not significantly different to that of $\mathrm{p} 110 \alpha \mathrm{EE}^{\mathrm{WT}} / \mathrm{p} 85 \alpha$ (Figure $2 \mathrm{~B}$, upper panel).

It is possible that the stoichiometry of phosphorylation of 5608 remains low after the 40 minute kinase reaction used, and thus lipid kinase activities of dephosphorylated and only partially phosphorylated $\mathrm{p} 110 \alpha \mathrm{EE} / \mathrm{p} 85 \alpha$ were compared in Figure 2B. We therefore performed a timecourse to determine whether a difference in activity of phosphorylated and dephosphorylated p110 $\alpha E E / p 85 \alpha$ became apparent with increasing levels of phosphorylation of p85 $\alpha$. Levels of phosphorylation of S608 became saturated after approximately 30 minutes (Figure 2C, upper panel). In some assays, the level of phosphorylation of the E545K mutant was apparently higher than wild-type PI3K $\alpha$ or the H1047R mutant, although this was an inconsistent observation and was not significantly different in most assays. When $\lambda$ phosphatase was added, lack of incorporation of ${ }^{32} \mathrm{P}$ into $\mathrm{p} 85 \alpha$ demonstrated that $\lambda$ phosphatase continued to dephosphorylate S608 throughout the assay. (Figure 2C, lower panel, closed symbols). Despite apparently saturating phosphorylation of S608 between 40 and 120 minutes, the difference in the PI kinase activity of phosphorylated 


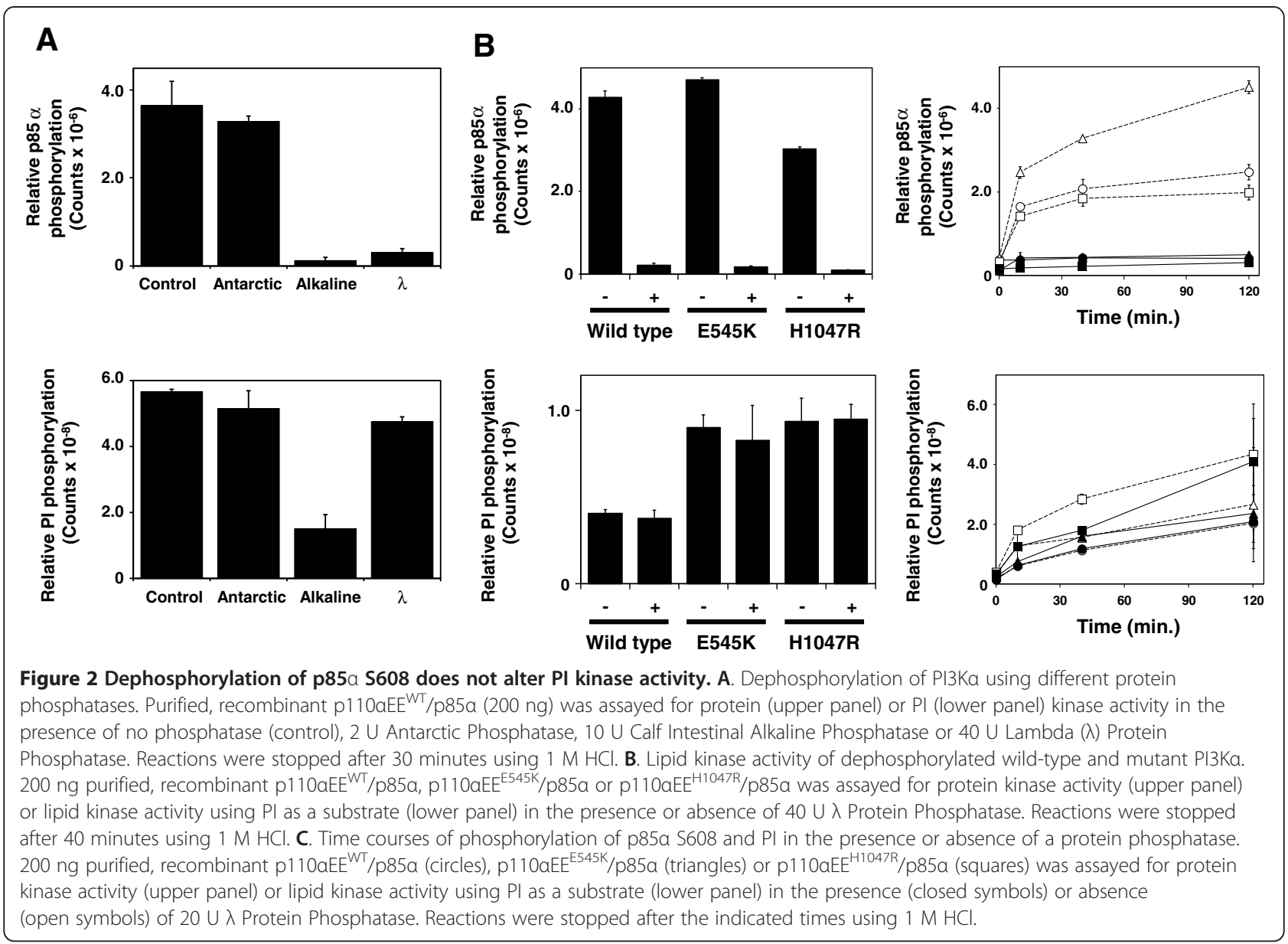

and dephosphorylated wild-type, E545K or H1047R $\mathrm{PI} 3 \mathrm{~K} \alpha$ did not increase over time (Figure 2C, lower panel), suggesting that phosphorylation of S608 does not regulate the PI kinase activity in either wild-type or mutant PI3K $\alpha$.

\section{Effect of phosphorylation of p85a S608 on PI3Ka lipid kinase activity}

To ensure that the apparent lack of difference in PI kinase activity of phosphorylated and dephosphorylated PI3K $\alpha$ was not due to a low stoichiometry of phosphorylation, even when levels were apparently saturated, we allowed the phosphorylation reaction to proceed for 16-24 hours using unlabelled ATP or no ATP for the mock phosphorylation reaction. Phosphorylated and mock-phosphorylated PI3K $\alpha$ were buffer exchanged to remove excess cold ATP, then the extent of phosphorylation of S608 was measured using MALDI-MS of tryptic digests of wild-type and mutant PI3K $\alpha$. Overlapping tryptic peptides containing $\mathrm{S} 608$ were observed at $\mathrm{m} / \mathrm{z}$ 3483.4 and $\mathrm{m} / \mathrm{z} 3611.5$ in mock or unphosphorylated PI3K $\alpha$ (Figure 3A, lower spectrum in each panel). Phosphorylation of $\mathrm{PI} 3 \mathrm{~K} \alpha$ led to the appearance of peptides at $\mathrm{m} / \mathrm{z} 3563.5$ and $\mathrm{m} / \mathrm{z} 3691.6$ (Figure 3A, upper spectrum in each panel), which are 80 mass units greater than the masses of the peptides containing nonphosphorylated S608 and suggest that these peptides incorporated one phosphate group per peptide. There was no evidence for phosphorylation of peptides other than those containing S608. To estimate the extent of phosphorylation of S608, we normalised the spectra to the height of a peptide at $\mathrm{m} / \mathrm{z} 3426.6$ that is not altered when PI3K $\alpha$ is phosphorylated, and compared the heights of the peaks of non-phosphorylated S608-containing peptides. Phosphorylation of $\mathrm{p} 110 \alpha \mathrm{EE}^{\mathrm{WT}} / \mathrm{p} 85 \alpha$ led to almost complete disappearance of the peaks at $\mathrm{m} / \mathrm{z} 3483.4$ and $\mathrm{m} / \mathrm{z} 3611.5$ corresponding to nonphosphorylated S608, suggesting that at least $90 \%$ of $\mathrm{p} 110 \alpha \mathrm{EE}^{\mathrm{WT}} / \mathrm{p} 85 \alpha$ was phosphorylated on S608 (Figure 3A, upper spectrum of panel 1). In support of this, the amount of ${ }^{32} \mathrm{P}$ incorporated into $\mathrm{p} 85 \alpha$ in a subsequent protein kinase time-course assay was negligible, suggesting that nearly all $\mathrm{S} 608$ residues were already occupied by an unlabelled phosphate group (Figure 3B, upper panel). The extent of phosphorylation of p85 $\alpha 608$ in $\mathrm{p} 110 \alpha \mathrm{EE}^{\mathrm{E} 545 \mathrm{~K}} / \mathrm{p} 85 \alpha$ and $\mathrm{p} 110 \alpha \mathrm{EE}^{\mathrm{H} 1047 \mathrm{R}} / \mathrm{p} 85 \alpha$ was less 


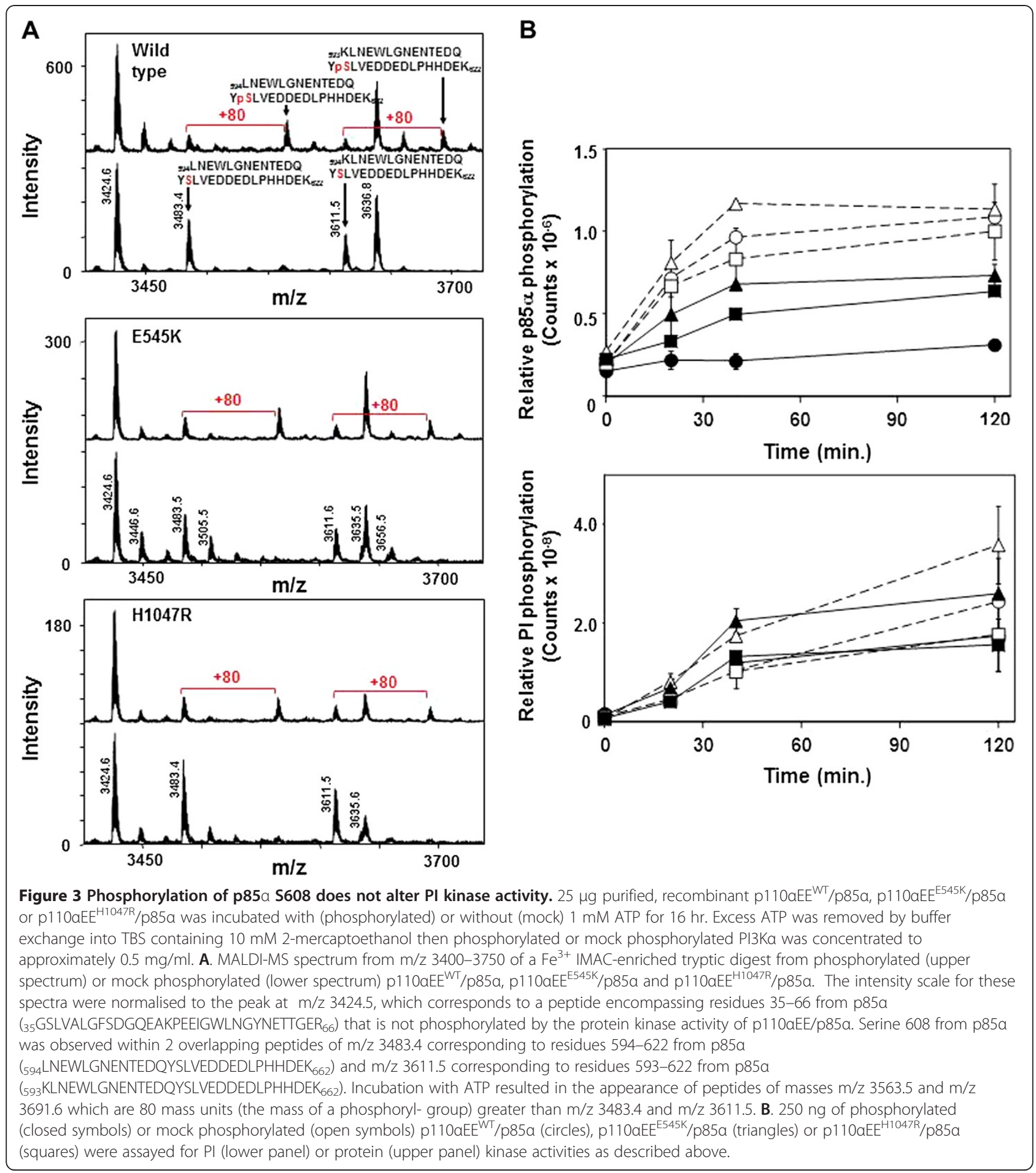

than that observed for $\mathrm{p} 110 \alpha \mathrm{EE} / \mathrm{WT} / \mathrm{p} 85 \alpha$, as the heights of the peaks at $\mathrm{m} / \mathrm{z} 3483.4$ and $\mathrm{m} / \mathrm{z} 3611.5$ were less decreased by phosphorylation compared to the height of the same peaks in mock-phosphorylated $\mathrm{p} 110 \alpha \mathrm{EE}^{\mathrm{E} 545 \mathrm{~K} /}$ $\mathrm{p} 85 \alpha$ and $\mathrm{p} 110 \alpha \mathrm{\alpha E}^{\mathrm{H} 1047 \mathrm{R}} / \mathrm{p} 85 \alpha$ (Figure 3A, panels $2 \& 3$ ), suggesting that a small proportion of mutant PI3Ka remained unphosphorylated after 16 hours. In agreement, low levels of ${ }^{32} \mathrm{P}$ were incorporated into $\mathrm{p} 85 \alpha$ in subsequent protein kinase time-course assays (Figure 3B, upper panel), suggesting that a small proportion of $\mathrm{S} 608$ in the E545K and H1047R mutants was not occupied by an unlabelled phosphate group. Nevertheless, the majority of $\mathrm{p} 110 \alpha \mathrm{EE}^{\mathrm{E} 545 \mathrm{~K}} / \mathrm{p} 85 \alpha$ and $\mathrm{p} 110 \alpha \mathrm{EE}^{\mathrm{H} 1047 \mathrm{R}} / \mathrm{p} 85 \alpha$ was phosphorylated on $\mathrm{S} 608$ under these conditions. 
The PI kinase activities of phosphorylated and mockphosphorylated wild-type PI3K $\alpha$ were not significantly different over a 2 hour time-course. Similarly, the PI kinase activities of phosphorylated and mock-phosphorylated E545K and H1047R PI3K $\alpha$ were not significantly different, although the activities of H1047R, and to a lesser extent E545K, were higher than that of wild-type PI3K $\alpha$. Nearly stoichiometric phosphorylation of S608 therefore did not affect the PI kinase activity of wild-type or mutant PI3K $\alpha$, further suggesting that phosphorylation of S608 does not regulate PI kinase activity.

\section{Discussion}

As reported previously for bovine PI3K $\alpha$ [18], we have successfully expressed and purified recombinant complexes of full-length human $\mathrm{p} 110 \alpha$ and $\mathrm{p} 85 \alpha$, the prototypic form of Class $1 \mathrm{~A}$ PI3K using the strategy of selecting for the of $\mathrm{p} 110 \alpha \mathrm{EE} / \mathrm{p} 85 \alpha$ complex by placing a 6 amino acid epitope tag at the C-terminus of the p110 $\alpha$, the subunit with limiting expression levels. The addition of C-terminal EE tag to p110 $\alpha$ did not appear to affect PI3K $\alpha$, as recombinant $\mathrm{p} 110 \alpha \mathrm{EE} / \mathrm{p} 85 \alpha$ had high stability and the expected activity and substrate specificity. High purity recombinant PI $3 K \alpha$ allowed us to assess the relative phosphoinositide lipid and protein kinase activities of wild-type and two common, tumourassociated mutants of PI3K $\alpha$.

Purified, recombinant oncogenic mutant forms of PI3K $\alpha$ had higher lipid kinase activities compared to wild-type PI3K $\alpha$ (Figure 1B) as expected [4-6,13]. The ATP $K_{m}$ was not significantly different between wildtype and mutant forms of PI3K $\alpha$ (Table 1) as previously reported [19]. However, there was a significant difference in ATP $V_{\max }$ when either PI or PI- $(4,5)-\mathrm{P}_{2}$ was used as a substrate, in agreement with a previous study [15]. This suggests that mutant forms of PI3K $\alpha$ phosphorylate and turn over inositol lipids more rapidly, rather than having inherent higher substrate affinities, thus generating increased levels of $\mathrm{PIP}_{3}$ and potentially partially explaining increased downstream signalling when the PI3K pathway is activated.

PI3K $\alpha$ also has protein kinase activity and has been reported to phosphorylate a number of protein substrates $[22,23]$ as well as its own $\mathrm{p} 85 \alpha$ regulatory subunit on $S 608[16,17,20]$. The role of $S 608$ phosphorylation in the regulation of PI3K $\alpha$ lipid kinase activity remains controversial. Despite previous reports that phosphorylation of S608 down-regulates the lipid kinase activity of the $110 \alpha$ catalytic subunit, we did not find any evidence to support this by in vitro manipulation of the levels of phosphorylation of $\mathrm{S} 608$ of purified, recombinant $\mathrm{p} 110 \alpha E E / \mathrm{p} 85 \alpha$ using either a protein phosphatase or saturating pre-phosphorylation. The reason for this discrepancy is not clear. In two studies, semi-purified recombinant PI3K $\alpha$ was used to show phosphorylation of 5608 reduces the lipid kinase activity of p110 $\alpha$ $[17,20]$. Semi-purified PI3K $\alpha$ can be unstable, thus it is possible that the apparent decrease in the lipid kinase activity of semi-purified PI3K $\alpha$ over time was due to p110 $\alpha$ degradation rather than S608 phosphorylation. A number of other studies have not observed a decrease in lipid kinase activity of recombinant, purified or immunoprecipitated PI3K $\alpha$ in time-course assays [24-27].

The time-course of $\mathrm{PIP}_{3}$ formation by endogenous PI3K in cells shows an initial increase, followed by a decrease in PIP $_{3}$ levels $[28,29]$, but this is largely due to the action of inositol 3- and 5-phosphatases that directly dephosphorylate $\mathrm{PIP}_{3}$ to form PI- $(4,5)-\mathrm{P}_{2}$ or PI-(3.4)- $\mathrm{P}_{2}$ respectively $[30,31]$. The phosphorylation of $\mathrm{S} 608$ in cells increases upon stimulation with insulin or PDGF [16], which mirrors activation of the lipid kinase activity of PI3K $\alpha$, thus it is not clear whether phosphorylation of S608 down-regulates endogenous PI3K $\alpha$ activity. Mutation of S608 to a non-phosphorylatable residue has been shown to decrease lipid kinase activity rather than increase it, as would be expected if mutation to alanine prevented phospho-S608-induced down regulation of PI kinase activity [16], suggesting that mutation of this residue, which resides in the interSH2 domain of p85 $\alpha$, affects PI3K $\alpha$ lipid kinase activity by altering the structure of PI3K $\alpha$ rather than by affecting the phosphorylation status.

Phosphorylation of S608 has also been reported to lead to dissociation of the $\mathrm{p} 85 \alpha$ and $\mathrm{p} 110 \alpha$ subunits [16]. Free $\mathrm{p} 110 \alpha$ has higher activity than $\mathrm{p} 110 \alpha$ in complex with $p 85 \alpha$ but is very unstable and is quickly degraded [32], thus it is possible that the decrease in lipid kinase activity when p85 $\alpha \mathrm{S} 608$ is phosphorylated could be explained by dissociation of $\mathrm{p} 110 \alpha$ and $\mathrm{p} 85 \alpha$ and rapid degradation of free p110 $\alpha$. However, our highly purified recombinant forms of $\mathrm{PI} 3 \mathrm{~K} \alpha$, when phosphorylated to saturation on $\mathrm{p} 85 \alpha$ S608, showed no evidence of subunit dissociation by size-exclusion chromatography and no evidence of $\mathrm{p} 110 \alpha$ degradation by SDS-PAGE (data not shown). The lack of observed dissociation, degradation or decrease in lipid kinase activity concomitant with increasing $\mathrm{p} 85 \alpha \mathrm{S} 608$ phosphorylation in our highly purified, recombinant PI3K $\alpha$ suggests that previous reports of S608 phosphorylation resulting in down-regulation of lipid kinase activity were due to the use semi-purified recombinant PI3Ka which is non-specifically degraded over time.

A number of mechanisms that regulate PI3K $\alpha$ enzymatic activity have been described, but no single event has been demonstrated to result in full activation of this enzyme. It is likely that full activation of PI3K $\alpha$ is a multi-step process. Within the $\mathrm{p} 110 \alpha / \mathrm{p} 85 \alpha$ complex, $\mathrm{p} 110 \alpha$ is both inhibited and structurally stabilised by tight binding to the p85a subunit [32]. Activation of the 
PI3K $\alpha$ involves protein-protein interactions that relieve the inhibition of the $p 110 \alpha$ kinase activity that is due to inter-subunit interactions of $\mathrm{p} 110 \alpha$ with the N-terminal $\mathrm{SH} 2$ and inter-SH2 domains of p85 $\alpha$ [33]. One mechanism of activation of $\mathrm{PI} 3 \mathrm{~K} \alpha$ is binding to specific phosphotyrosine-containing motifs (pYXXM) present in receptor tyrosine kinases (RTKs) and cytoplasmic signalling proteins, such as IRS-1, to the $\mathrm{p} 85 \alpha \mathrm{N}$ - and Cterminal $\mathrm{SH} 2$ domains [34-36], which disrupts the inhibitory contact between the p85 $\alpha$ N-terminal SH2 and the p110 $\alpha$ catalytic domain $[37,38]$. The E545K mutation is thought to increase activity by disrupting the p $85 \alpha$ N-terminal SH2/p110 $\alpha$ interface, similar to binding of RTKs $[37,38]$. Binding of a range of other intracellular proteins, such as activated Ras, $\mathrm{SH} 3$ domain-containing proteins and small GTPases, have also been reported to activate PI3K $\alpha$ [39-41] but it is not clear whether binding of these ligands directly activates enzyme activity or whether binding results in activation by translocating PI3K $\alpha$ to the plasma membrane, where its lipid substrate is located [42,43]. Tyrosine phosphorylation of $p 85 \alpha$ Y688 by Src family tyrosine kinases has also been shown to increase PI3K $\alpha$ activity [44], but the mechanism is not known.

Phosphorylation of p85 $\alpha$ S652 by PKC [45] (as well as p $85 \alpha$ S608 by $p 110 \alpha$ ) has been reported to decrease $\mathrm{PI} 3 \mathrm{~K} \alpha$ activity. S608 is in the inter-SH2 domain of $\mathrm{p} 85 \alpha$, but is not within the section that has been observed to contact p110 $\alpha[37,38,46]$, therefore it is not clear whether phosphorylation of S608 could influence the inter-subunit interactions of $\mathrm{p} 110 \alpha$ and $\mathrm{p} 85 \alpha$. A model of the structure of p110 with the $\mathrm{N}$ - terminal $\mathrm{SH} 2, \mathrm{C}$ terminal $\mathrm{SH} 2$ and inter-SH2 domains of p85 [47] suggests that the $\mathrm{C}$-terminal part of the inter-SH2 domain (containing S608) and the C-terminal $\mathrm{SH} 2$ domain has the potential to contact the catalytic domain of p110. Activation of PI3K $\alpha$ due to binding of the $\mathrm{p} 85 \alpha \mathrm{C}$ terminal $\mathrm{SH} 2$ domain to phosphotyrosine-containing proteins would be expected to be due to a conformational change that disrupts the interface between the p $85 \alpha$ C-terminal SH2 domain and the p110 $\alpha$ catalytic domain, analogous to the disruption of the inhibitory contact between the p $85 \alpha$ N-terminal $\mathrm{SH} 2$ and the p $110 \alpha$ catalytic domain. In contrast, for phosphorylation of S608 to decrease PI3K $\alpha$ enzymatic activity, it would have to stabilise this interface and oppose the phosphotyrosine binding-induced disruption. Regulation of PI3K $\alpha$ by stabilisation of inter-subunit interactions has not yet been demonstrated.

\section{Conclusions}

Studies showing a decrease in PI kinase activity of wildtype PI3K $\alpha$ that correlated with increasing p85 $\alpha$ S608 phosphorylation suggested the possibility that decreased
S608 phosphorylation of oncogenic PI3K $\alpha$ could be a mechanism underlying its increased PI kinase activity. This study, in which highly purified, recombinant wildtype and oncogenic, mutant PI3K $\alpha$ was dephosphorylated or fully phosphorylated on serine 608 in vitro (thus avoiding point mutations which can potentially alter protein structure and activity), found no evidence that phosphorylation of S608 influenced PI kinase activity. In addition, levels of phosphorylation of oncogenic PI3K $\alpha$ were not different to that of wild-type PI3K $\alpha$.

\section{Methods}

\section{Production of recombinant proteins}

cDNAs encoding full-length human p85 $\alpha$ (PIK3R1_HUMAN, [Uniprot: P27986], aa1-724) or full-length human wild-type or mutant (E545K or H1047R) p110 $\alpha$ (PIK3CA_HUMAN, [Uniprot: P42336], aa1-1068) with an additional C-terminal spacer (PGG) and a Glu- or EEepitope tag (EFMPME) $[18,48]$ were subcloned into the transfer plasmid pBlueBac4. Recombinant baculoviruses were produced by co-transfection of these transfer plasmids into Sf9 insect cells with Bac-N-Blue baculovirus DNA (Invitrogen), then plaque purified and amplified as described [49]. EE-epitope tagged p110 $\alpha$ (p110 $\alpha E E)$ and p $85 \alpha$ were co-expressed in exponentially growing Sf9 cells (density $=1.5-2 \times 10^{6}$ cells $/ \mathrm{ml}$ ) by infection with recombinant baculoviruses at a multiplicity of infection (MOI) of between 1 and 10. Wild-type or mutant p $110 \alpha E E / p 85 \alpha$ complexes were purified to homogeneity by anti-EE tag affinity chromatography and anion exchange chromatography as previously described $[18,50]$. The concentrations of purified, recombinant PI3Ks were quantified by UV spectroscopy using a molar extinction coefficient of $264115 \mathrm{M}^{-1} \mathrm{~cm}^{-1}$.

\section{Gel electrophoresis}

Recombinant $\mathrm{p} 110 \alpha \mathrm{EE} / \mathrm{p} 85 \alpha$ complexes were separated by SDS-PAGE using 10\% Tris-glycine gels. Fast Coomassie Blue staining and destaining was carried out using a microwave oven as described [51].

\section{Phosphoinositide 3-kinase assays}

PI3K assays were carried out essentially as previously described [18,52,53] in $20 \mathrm{mM}$ Tris pH7.5, $150 \mathrm{mM}$ $\mathrm{NaCl}$ (TBS) containing $5 \mathrm{mM}$ 2-mercaptoethanol. PI kinase assays contained $2 \mathrm{mM} \mathrm{MgCl} 2,2 \mathrm{mM} \mathrm{MnCl}$, $0.2 \mathrm{mM}$ ATP, $5-10 \mu \mathrm{Ci}\left[{ }^{32} \mathrm{P}\right] \gamma \mathrm{ATP}, 500 \mu \mathrm{g} / \mathrm{ml}$ of phosphatidylinositol (PI) and $250 \mu \mathrm{g} / \mathrm{ml}$ of phosphatidylserine (PS). Extracted phospholipids were separated by thin layer chromatography in 65\% 1-propanol, $0.7 \mathrm{M}$ acetic acid, $50 \mathrm{mM}$ phosphoric acid, exposed to a phosphor screen (Molecular Dynamics) and analysed using ImageQuant software (GE Healthcare). Michaelis-Menten kinetics for phosphorylation of PI and PI- $(4,5)-\mathrm{P}_{2}$ were 
calculated from initial reaction rates in assays in which the concentration of ATP was varied between 0 and $125 \mu \mathrm{M}$. Reactions were stopped after $20 \mathrm{~min}$ using $1 \mathrm{M} \mathrm{HCl}$.

\section{Protein kinase assays}

Protein kinase assays were carried out in TBS containing $2 \mathrm{mM} \mathrm{MgCl}_{2}, 2 \mathrm{mM} \mathrm{MnCl} 2,0.2 \mathrm{mM} \mathrm{ATP}$ and 5-10 $\mu \mathrm{Ci}$ $\left[{ }^{32} \mathrm{P}\right]$ 个ATP. Phosphorylated proteins were separated from free $\left[{ }^{32} \mathrm{P}\right]$ 个ATP by SDS-PAGE as described above. Gels were fixed and stained with Coomassie Blue, then dried, exposed to a phosphor screen and analysed as described above.

\section{Phosphatase treatment}

500 ng recombinant PI3K was mixed with 2-10 U recombinant Calf Intestinal Alkaline Phosphatase, 0.5-2 U Antarctic Phosphatase or 8-40 U Lambda $(\lambda)$ Protein Phosphatase (NEB) and assayed for PI kinase activity or protein kinase activity as described above.

\section{In vitro phosphorylation of recombinant p110aEE/p85a}

$25 \mu \mathrm{g}$ purified wild type or mutant $\mathrm{p} 110 \alpha \mathrm{EE} / \mathrm{p} 85 \alpha \mathrm{com}-$ plex was incubated with or without $1 \mathrm{mM}$ ATP in the presence of $20 \mathrm{mM}$ Tris $\mathrm{pH} 7.5,150 \mathrm{mM} \mathrm{NaCl}, 5 \mathrm{mM}$ 2-mercaptoethanol, $2 \mathrm{mM} \mathrm{MgCl}$ and $2 \mathrm{mM} \mathrm{MnCl}_{2}$ at room temperature for $16 \mathrm{hr}$. Phosphorylated or mock phosphorylated PI3K $\alpha$ was buffer exchanged into TBS containing $10 \mathrm{mM}$ 2-mercaptoethanol using Sephadex G-25 (GE Life Sciences) and concentrated using centrifugal filters (Amicon Ultra15 10,000 NMWL, Millipore). 250 ng of phosphorylated or mock phosphorylated (control) PI3K $\alpha$ was assayed for PI kinase activity or protein kinase activity as described above.

Phosphorylation sites on $\mathrm{p} 110 \alpha \mathrm{EE} / \mathrm{p} 85 \alpha$ were mapped by digesting $2 \mu \mathrm{g}$ aliquots of phosphorylated or mock phosphorylated $\mathrm{p} 110 \alpha \mathrm{EE} / \mathrm{p} 85 \alpha$ with $0.1 \mu \mathrm{g}$ trypsin (Worthington) then purifying phosphopeptides using $\mathrm{Fe}^{3}$ ${ }^{+}$immobilised metal affinity chromatography (IMAC) as described [54]. Phosphopeptides were identified by peptide mass fingerprinting using a QSTAR oMALDIQqTOF (Applied Biosystems/PE Sciex).

\section{Competing interests}

The authors declare that they have no competing interests.

\section{Authors' contributions}

MJL designed the experiments; MJL, MS and NLC performed the experiments; MJL, MS, RBP and WAP analysed the data; MJL, WAP and RBP interpreted the data; MJL, WAP and RBP wrote the manuscript; MJL, WAP, RBP and CAM revised the manuscript; WAP and CAM gave final approval of the version to be published. All authors read and approved the final manuscript.

\section{Acknowledgements}

This research was supported by a Grant-in-Aid from the Cancer Council victoria.

\section{Author details}

'The Department of Biochemistry and Molecular Biology, Monash University, Clayton, VIC 3800, Australia. ${ }^{2}$ Surgical Oncology Research Laboratory, Peter MacCallum Cancer Centre, St Andrew's Place, East Melbourne, VIC 3002, Australia. ${ }^{3}$ Cancer Signalling Laboratory, Peter MacCallum Cancer Centre, St Andrew's Place, East Melbourne, VIC 3002, Australia. ${ }^{4}$ Sir Peter MacCallum Department of Oncology, University of Melbourne, Parkville, VIC 3010, Australia. ${ }^{5}$ Department of Surgery, St. Vincent's Hospital, University of Melbourne, Parkville, VIC 3010, Australia. ${ }^{6}$ Department of Biochemistry and Molecular Biology, University of Melbourne, Parkville, VIC 3010, Australia. ${ }^{7}$ The Ludwig Institute for Cancer Research, Royal Melbourne Hospital, PO Box 2008, Parkville 3050, Australia.

Received: 28 October 2012 Accepted: 22 December 2012

Published: 27 December 2012

\section{References}

1. Vanhaesebroeck B, Stephens L, Hawkins P: PI3K signalling: the path to discovery and understanding. Nat Rev Mol Cell Biol 2012, 13(3):195-203.

2. Lemmon MA: Membrane recognition by phospholipid-binding domains. Nat Rev Mol Cell Biol 2008, 9(2):99-111.

3. Cantley LC: The phosphoinositide 3-kinase pathway. Science 2002, 296(5573):1655-1657.

4. Samuels Y, Wang Z, Bardelli A, Silliman N, Ptak J, Szabo S, Yan H, Gazdar A, Powell SM, Riggins GJ, Willson JK, Markowitz S, Kinzler KW, Vogelstein B, Velculescu VE: High frequency of mutations of the PIK3CA gene in human cancers. Science 2004, 304(5670):554.

5. Kang S, Bader AG, Vogt PK: Phosphatidylinositol 3-kinase mutations identified in human cancer are oncogenic. Proc Natl Acad Sci U S A 2005 102(3):802-807.

6. Isakoff SJ, Engelman JA, Irie HY, Luo J, Brachmann SM, Pearline RV, Cantley LC, Brugge JS: Breast cancer-associated PIK3CA mutations are oncogenic in mammary epithelial cells. Cancer Res 2005, 65(23):10992-11000.

7. Bader AG, Kang S, Vogt PK: Cancer-specific mutations in PIK3CA are oncogenic in vivo. Proc Natl Acad Sci U S A 2006, 103(5):1475-1479.

8. Bachman KE, Argani P, Samuels Y, Silliman N, Ptak J, Szabo S, Konishi H, Karakas B, Blair BG, Lin C, Peters BA, Velculescu VE, Park BH: The PIK3CA gene is mutated with high frequency in human breast cancers. Cancer Biol Ther 2004, 3(8):772-775.

9. Campbell IG, Russell SE, Choong DY, Montgomery KG, Ciavarella ML, Hooi CS, Cristiano BE, Pearson RB, Phillips WA: Mutation of the PIK3CA gene in ovarian and breast cancer. Cancer Res 2004, 64(21):7678-7681.

10. Velho S, Oliveira C, Ferreira A, Ferreira AC, Suriano G, Schwartz S Jr, Duval A, Carneiro F, Machado JC, Hamelin R, Seruca R: The prevalence of PIK3CA mutations in gastric and colon cancer. Eur J Cancer 2005, 41(11):1649-1654.

11. Miyaki M, lijima T, Yamaguchi T, Takahashi K, Matsumoto $H$, Yasutome M, Funata N, Mori T: Mutations of the PIK3CA gene in hereditary colorectal cancers. Int J Cancer 2007, 121(7):1627-1630.

12. Liu P, Cheng H, Roberts TM, Zhao JJ: Targeting the phosphoinositide 3-kinase pathway in cancer. Nat Rev Drug Discov 2009, 8(8):627-644.

13. Ikenoue T, Kanai F, Hikiba Y, Obata T, Tanaka Y, Imamura J, Ohta M, Jazag A, Guleng B, Tateishi K, Asaoka Y, Matsumura M, Kawabe T, Omata M: Functional analysis of PIK3CA gene mutations in human colorectal cancer. Cancer Res 2005, 65(11):4562-4567.

14. Zhao JJ, Liu Z, Wang L, Shin E, Loda MF, Roberts TM: The oncogenic properties of mutant p110alpha and p110beta phosphatidylinositol 3-kinases in human mammary epithelial cells. Proc Natl Acad Sci U S A 2005, 102(51):18443-18448.

15. Chaussade C, Cho K, Mawson C, Rewcastle GW, Shepherd PR: Functional differences between two classes of oncogenic mutation in the PIK3CA gene. Biochem Biophys Res Commun 2009, 381(4):577-581.

16. Foukas LC, Beeton CA, Jensen J, Phillips WA, Shepherd PR: Regulation of phosphoinositide 3-kinase by its intrinsic serine kinase activity in vivo. Mol Cell Biol 2004, 24(3):966-975.

17. Dhand R, Hiles I, Panayotou G, Roche S, Fry MJ, Gout I, Totty NF, Truong O, Vicendo P, Yonezawa K, et al: PI 3-kinase is a dual specificity enzyme: autoregulation by an intrinsic protein-serine kinase activity. EMBO J 1994, 13(3):522-533

18. Layton MJ, Harpur AG, Panayotou G, Bastiaens PI, Waterfield MD: Binding of a diphosphotyrosine-containing peptide that mimics activated 
platelet-derived growth factor receptor beta induces oligomerization of phosphatidylinositol 3-kinase. J Biol Chem 1998, 273(50):33379-33385.

19. Carson JD, Van Aller G, Lehr R, Sinnamon RH, Kirkpatrick RB, Auger KR, Dhanak D, Copeland RA, Gontarek RR, Tummino PJ, Luo L: Effects of oncogenic p110alpha subunit mutations on the lipid kinase activity of phosphoinositide 3-kinase. Biochem J 2008, 409(2):519-524.

20. Carpenter CL, Auger KR, Duckworth BC, Hou WM, Schaffhausen B, Cantley LC: A tightly associated serine/threonine protein kinase regulates phosphoinositide 3-kinase activity. Mol Cell Biol 1993, 13(3):1657-1665.

21. Layton MJ, Church NL, Faux MC, Ji H, Goode RJ, Kapp EA, Burgess AW, Simpson RJ: Solubilisation of the armadillo-repeat protein beta-catenin using a zwitterionic detergent allows resolution of phosphorylated forms by 2DE. Electrophoresis 2012, 33(12):1804-1813.

22. Lam K, Carpenter CL, Ruderman NB, Friel JC, Kelly KL: The phosphatidylinositol 3-kinase serine kinase phosphorylates IRS-1. Stimulation by insulin and inhibition by wortmannin. J Biol Chem 1994, 269(32):20648-20652.

23. Foukas LC, Shepherd PR: elF4E Binding protein 1 and H-Ras are novel substrates for the protein kinase activity of class-I phosphoinositide 3-kinase. Biochem Biophys Res Commun 2004, 319(2):541-549.

24. Beeton CA, Chance EM, Foukas LC, Shepherd PR: Comparison of the kinetic properties of the lipid- and protein-kinase activities of the p110alpha and p110beta catalytic subunits of class-la phosphoinositide 3-kinases. Biochem J 2000, 350(Pt 2):353-359.

25. Ruiz-Larrea F, Vicendo P, Yaish P, End P, Panayotou G, Fry MJ, Morgan SJ, Thompson A, Parker PJ, Waterfield MD: Characterization of the bovine brain cytosolic phosphatidylinositol 3-kinase complex. Biochem J 1993, 290(Pt 2):609-616.

26. Michell RH, Harwood JL, Coleman R, Hawthorne JN: Characteristics of rat liver phosphatidylinositol kinase and its presence in the plasma membrane. Biochim Biophys Acta 1967, 144(3):649-658.

27. Van Aller GS, Carson JD, Fernandes C, Lehr R, Sinnamon RH, Kirkpatrick RB, Tummino PJ, Luo L: Characterization of PI3K class IA isoforms with regulatory subunit p55alpha using a scintillation proximity assay. Anal Biochem 2008, 383(2):311-315.

28. Stephens L, Jackson T, Hawkins PT: Synthesis of phosphatidylinositol 3,4,5-trisphosphate in permeabilized neutrophils regulated by receptors and G-proteins. J Biol Chem 1993, 268(23):17162-17172.

29. van der Kaay J, Batty IH, Cross DA, Watt PW, Downes CP: A novel, rapid, and highly sensitive mass assay for phosphatidylinositol 3,4,5-trisphosphate (Ptdlns(3,4,5)P3) and its application to measure insulin-stimulated Ptdlns(3,4,5)P3 production in rat skeletal muscle in vivo. J Biol Chem 1997, 272(9):5477-5481.

30. Sasaki T, Takasuga S, Sasaki J, Kofuji S, Eguchi S, Yamazaki M, Suzuki A: Mammalian phosphoinositide kinases and phosphatases. Prog Lipid Res 2009, 48(6):307-343.

31. Dyson JM, Fedele CG, Davies EM, Becanovic J, Mitchell CA: Phosphoinositide phosphatases: just as important as the kinases. Sub-cellular biochemistry 2012, 58:215-279.

32. Yu J, Zhang Y, Mcllroy J, Rordorf-Nikolic T, Orr GA, Backer JM: Regulation of the p85/p110 phosphatidylinositol 3'-kinase: stabilization and inhibition of the $\mathrm{p} 110 \mathrm{alpha}$ catalytic subunit by the $\mathrm{p} 85$ regulatory subunit. $\mathrm{Mo}$ Cell Biol 1998, 18(3):1379-1387.

33. Yu J, Wjasow C, Backer JM: Regulation of the p85/p110alpha phosphatidylinositol 3'-kinase. Distinct roles for the n-terminal and c-terminal SH2 domains. J Biol Chem 273, 273(46):30199-30203.

34. Backer JM, Myers MG Jr, Shoelson SE, Chin DJ, Sun XJ, Miralpeix M, Hu P, Margolis B, Skolnik EY, Schlessinger J, et al: Phosphatidylinositol 3'-kinase is activated by association with IRS-1 during insulin stimulation. EMBO J 1992, 11(9):3469-3479.

35. Rordorf-Nikolic T, Van Horn DJ, Chen D, White MF, Backer JM: Regulation of phosphatidylinositol 3'-kinase by tyrosyl phosphoproteins. Full activation requires occupancy of both $\mathrm{SH} 2$ domains in the $85-\mathrm{kDa}$ regulatory subunit. J Biol Chem 1995, 270(8):3662-3666.

36. Carpenter $C L$, Auger KR, Chanudhuri M, Yoakim M, Schaffhausen B, Shoelson S, Cantley LC: Phosphoinositide 3-kinase is activated by phosphopeptides that bind to the $\mathrm{SH} 2$ domains of the $85-\mathrm{kDa}$ subunit. J Biol Chem 1993, 268(13):9478-9483.

37. Miled N, Yan Y, Hon WC, Perisic O, Zvelebil M, Inbar Y, SchneidmanDuhovny D, Wolfson HJ, Backer JM, Williams RL: Mechanism of two classes of cancer mutations in the phosphoinositide 3-kinase catalytic subunit. Science 2007, 317(5835):239-242.

38. Mandelker D, Gabelli SB, Schmidt-Kittler O, Zhu J, Cheong I, Huang CH, Kinzler KW, Vogelstein B, Amzel LM: A frequent kinase domain mutation that changes the interaction between PI3Kalpha and the membrane. Proc Natl Acad Sci U S A 2009, 106(40):16996-17001.

39. Rodriguez-Viciana P, Warne PH, Dhand R, Vanhaesebroeck B, Gout I, Fry MJ, Waterfield MD, Downward J: Phosphatidylinositol-3-OH kinase as a direct target of Ras. Nature 1994, 370(6490):527-532

40. Pleiman CM, Hertz WM, Cambier JC: Activation of phosphatidylinositol-3' kinase by Src-family kinase SH3 binding to the p85 subunit. Science 1994, 263(5153):1609-1612.

41. Tolias KF, Cantley LC, Carpenter CL: Rho family GTPases bind to phosphoinositide kinases. J Biol Chem 1995, 270(30):17656-17659.

42. Klippel A, Reinhard C, Kavanaugh WM, Apell G, Escobedo MA, Williams LT: Membrane localization of phosphatidylinositol 3-kinase is sufficient to activate multiple signal-transducing kinase pathways. Mol Cell Biol 1996, 16(8):4117-4127

43. Rodriguez-Viciana P, Warne PH, Vanhaesebroeck B, Waterfield MD Downward J: Activation of phosphoinositide 3-kinase by interaction with Ras and by point mutation. EMBO J 1996, 15(10):2442-2451.

44. von Willebrand M, Williams S, Saxena M, Gilman J, Tailor P, Jascur T, Amarante-Mendes GP, Green DR, Mustelin T: Modification of phosphatidylinositol 3-kinase $\mathrm{SH} 2$ domain binding properties by Abl- or Lck-mediated tyrosine phosphorylation at Tyr-688. J Biol Chem 1998, 273(7):3994-4000.

45. Lee JY, Chiu YH, Asara J, Cantley LC: Inhibition of PI3K binding to activators by serine phosphorylation of $\mathrm{PI} 3 \mathrm{~K}$ regulatory subunit p85alpha Src homology-2 domains. Proc Natl Acad Sci U S A 2011, 108(34):14157-14162.

46. Huang $\mathrm{CH}$, Mandelker D, Schmidt-Kittler O, Samuels Y, Velculescu VE, Kinzler KW, Vogelstein B, Gabelli SB, Amzel LM: The structure of a human p110alpha/p85alpha complex elucidates the effects of oncogenic PI3Kalpha mutations. Science 2007, 318(5857):1744-1748.

47. Vadas O, Burke JE, Zhang X, Berndt A, Williams RL: Structural basis for activation and inhibition of class I phosphoinositide 3-kinases. Sci Signal 2011, 4(195):re2.

48. Porfiri E, Evans T, Chardin P, Hancock JF: Prenylation of Ras proteins is required for efficient hSOS1-promoted guanine nucleotide exchange. J Biol Chem 1994, 269(36):22672-22677.

49. O'Reilly DR, Miller LK, Luckow VA: Baculovirus expression vectors: a laboratory manual. Oxford: Oxford University Press; 1994.

50. Catimel B, Layton M, Church N, Ross J, Condron M, Faux M, Simpson RJ, Burgess AW, Nice EC: In situ phosphorylation of immobilized receptors on biosensor surfaces: application to E-cadherin/beta-catenin interactions. Anal Biochem 2006, 357(2):277-288.

51. Wong C, Sridhara S, Bardwell JC, Jakob U: Heating greatly speeds coomassie blue staining and destaining. Biotechniques 2000, 28(3):426-428. 430, 432.

52. Whitman M, Kaplan DR, Schaffhausen B, Cantley L, Roberts TM: Association of phosphatidylinositol kinase activity with polyoma middle-T competent for transformation. Nature 1985, 315(6016):239-242.

53. Arcaro A, Volinia S, Zvelebil MJ, Stein R, Watton SJ, Layton MJ, Gout I, Ahmadi K, Downward J, Waterfield MD: Human phosphoinositide 3-kinase C2beta, the role of calcium and the C2 domain in enzyme activity. J Biol Chem 1998, 273(49):33082-33090.

54. Stensballe A, Steen $H$, Jensen ON: Proteomic methods for phosphorylation site mapping. In Proteins and proteomics: a laboratory manual. Edited by Simpson RJ. Cold Spring Harbor, NY: Cold Spring Harbor Laboratory Press; 2003:926. xiii.

doi:10.1186/1471-2091-13-30

Cite this article as: Layton et al:: Autophosphorylation of serine 608 in the p85 regulatory subunit of wild type or cancer-associated mutants of phosphoinositide 3-kinase does not affect its lipid kinase activity. BMC Biochemistry 2012 13:30. 